\title{
INFLUÊNCIA DA CONVIVÊNCIA DO CAPIM-AMARGOSO NA QUALIDADE DE SEMENTES DE SOJA
}

\section{SOURGRASS COEXISTENCE INFLUENCES ON SOYBEAN SEED QUALITY}

Iara Martins de Paula ${ }^{\mathrm{a}}$, Guilherme Braga Pereira Braz ${ }^{\mathrm{a} *}$, Rafael Romero Mendes ${ }^{\mathrm{b}}$, Alan Bruno Caneppele ${ }^{\mathrm{a}}$, Alessandro Guerra da Silva ${ }^{\mathrm{a}}$, Aline Guimarães Cruvinel $^{\mathrm{a}}$

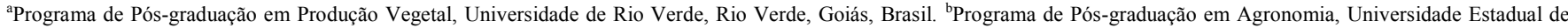
Maringá, Maringá, Paraná, Brasil.

*Autor correspondente: guilhermebrag@gmail.com.

\section{INFORMAÇÕES DO ARTIGO}

\section{Histórico do artigo:}

Recebido: 09 Outubro 2019.

Aceito: 20 Julho 2020

Publicado: 03 Agosto 2020.

\section{Palavras-chave/Keywords:}

Digitaria insularis/ Digitaria insularis.

Glycine max/ Glycine max.

Interferência/ Interference.

Produção de sementes/ Seeds production.

\section{Financiamento:}

$\begin{array}{lrr}\text { Conselho } & \text { Nacional } & \text { de } \\ \text { Desenvolvimento } & \text { Científico } & \text { e } \\ \text { Tecnológico }(\mathrm{CNPq}) \text {. } & & \end{array}$

Direito Autoral: Este é um artigo de acesso aberto distribuído sob os termos da Licença Creative Commons, que permite uso, distribuição e reprodução irrestritos em qualquer meio, desde que $\mathrm{o}$ autor e a fonte originais sejam creditados.

\section{Citação deste artigo:}

PAULA, I. M.; BRAZ, G. B. P.; MENDES, R. R.; CANEPPELE, A. B.; SILVA, A. G.; CRUVINEL, A. G. Influência da convivência do capimamargoso na qualidade de sementes de soja. Revista Brasileira de Herbicidas, v. 19, n. 1. 2020.

\section{RESUMO}

A infestação de capim-amargoso (Digitaria insularis) é responsável por grande parte das perdas de produtividade em lavouras de soja (Glycine max). Entretanto, pouco se tem estudado sobre a interferência desta espécie na produção de grãos para sementes. O objetivo deste estudo foi avaliar a interferência de capim-amargoso sobre a qualidade de sementes de soja. Um experimento foi instalado para estudar cinco densidades de capim-amargoso $(0,2$, 4,6 e 8 plantas $\mathrm{m}^{-2}$ ) em duas cultivares $\left(\right.$ Garra IPRO $^{\circledR}$ e ST797 IPRO ${ }^{\circledR}$ ). Os danos na maior densidade avaliada ( 8 plantas $\mathrm{m}^{-2}$ ) foram de perda de $16 \%$ no número de sementes normais, $32 \%$ a mais de sementes mortas e $16 \%$ de perda na germinação para a cultivar ST797 IPRO $^{\circledR}$. A cultivar Garra IPRO ${ }^{\circledR}$ não apresentou diferenças nestas variáveis, sugerindo melhor habilidade competitiva em relação a cultivar ST797 IPRO $^{\circledR}$. Quanto maior a infestação de capim-amargoso na soja, maiores as chances de perda na qualidade de sementes. O nível de dano às sementes pela presença de capim-amargoso depende da habilidade competitiva de cada cultivar.

\section{ABSTRACT}

Sourgrass (Digitaria insularis) infestation is one of the great responsible for soybean (Glycine max) yield losses. However, a few studies are demonstrating its interference in soybean seed production fields. The aim of this study was to evaluate the sourgrass interference on soybean seed quality. An experiment was conducted to analyze five sourgrass density $\left(0,2,4,6\right.$ and 8 plants $\left.\mathrm{m}^{-2}\right)$ in two commercial soybean cultivars (Garra IPRO $^{\circledR}$ and ST797 IPRO $\left.^{\circledR}\right)$. The damage in the highest sourgrass density $\left(8\right.$ plants $\left.\mathrm{m}^{-2}\right)$ resulted in losses of $16 \%$ in the normal seeds number, increasing in $32 \%$ of dead seeds, and $16 \%$ of germination losses for ST797 IPRO $^{\circledR}$. Garra IPRO ${ }^{\circledR}$ cultivar has not shown differences in those variables, suggesting better competitiveness than ST797 IPRO ${ }^{\circledR}$ cultivar. The higher interference of sourgrass in soybean, the higher is the probability of losses in seed quality. The magnitude of damage to seeds depends on competitiveness of each variety. 


\section{Introdução}

O capim-amargoso (Digitaria insularis) tem sido relatado como uma das plantas daninhas mais preocupantes dos sistemas de produção brasileiros. A agressividade e o rápido estabelecimento em áreas de plantio direto são um dos motivos pelos quais esta espécie encontra-se disseminada em praticamente todos os Estados produtores de grãos do Brasil, com destaque para o Paraná, Mato Grosso do Sul, São Paulo, Mato Grosso, Goiás e Bahia (LICORINI et al., 2015; OVEJERO et al., 2017).

O capim-amargoso é uma gramínea perene de ciclo $\mathrm{C} 4$, ou seja, com elevada eficiência de uso da água e nutrientes do solo e rápido crescimento (GEMELLI et al., 2012). As plantas de capim-amargoso podem chegar a 100 $\mathrm{cm}$ de altura, com acúmulo de massa seca exponencial aos 40 dias após a emergência, o que coincide com a formação de estruturas de reserva (ADEGAS et al., 2019). Em temperaturas entre 15 e $30^{\circ} \mathrm{C}$ e fotoperíodo de 10 a $12 \mathrm{~h}$, a taxa de germinação das sementes de capim-amargoso ultrapassa 80\% (MARTINS; BARROSO; ALVES, 2017). Além da reprodução por sementes, o capim-amargoso também apresenta reprodução vegetativa por meio de propágulos denominados rizomas. Com o estabelecimento do plantio direto, o revolvimento do solo com gradagens e arações deixou de ser um método mecânico de controle de capim-amargoso, permitindo a reprodução e o crescimento por meio dos rizomas (GEMELLI et al., 2012).

A soja (Glycine max) ocupou mais de 35 milhões de hectares com produção de mais de 115 milhões de toneladas de grãos na safra 2018/2019 (CONAB, 2019), o que demonstra a importância da cultura para a economia do país. Mais de $72 \%$ das lavouras de soja são estabelecidas com o uso de sementes comerciais. A qualidade de sementes é garantida por padrões mínimos de germinação, pureza e sanidade e estes índices são fundamentais para o bom estabelecimento da lavoura e consequentemente para a otimização da produtividade (OLIVEIRA NETO, 2016).

Para o capim-amargoso em convivência com a soja tem sido relatado que as perdas podem ser de $320 \mathrm{~kg} \mathrm{ha}^{-1} \mathrm{a}$ cada 1,2 plantas adultas $\mathrm{m}^{-2}$ (GAZZIERO et al., 2019). Correia et al. (2019) reportaram perda de $26 \%$ da produtividade a cada planta $\mathrm{m}^{-1}$ de capim-amargoso em convivência com a cultura. Apesar destes estudos, pouco se sabe sobre a influência da interferência desta planta daninha na qualidade das sementes de soja. Os trabalhos atuais envolvendo a interferência das plantas daninhas na soja têm se preocupado em mensurar as perdas de produtividade ou da qualidade do produto final (VITORINO et al., 2017; BARNES et al., 2018; GAZZIERO et al., 2019), existindo escassez de informações na literatura sobre a interferência de plantas daninhas na produção de sementes desta cultura.

O presente estudo, portanto, apresenta a hipótese de que quanto maior o nível de infestação de capim-amargoso na soja, maior é a queda na qualidade de sementes produzidas. Neste sentido, o objetivo ao desenvolver o presente trabalho foi avaliar a qualidade de sementes de soja em função da densidade de infestação de capim-amargoso em duas cultivares de grupo de maturação distintos.

\section{Material e Métodos}

Um experimento foi conduzido à campo na Universidade de Rio Verde, Rio Verde (Goiás), nas coordenadas geográficas $17^{\circ} 47^{\prime} 18.67^{\prime \prime} \mathrm{S} ; 50^{\circ} 57^{\prime} 27.67^{\prime \prime O}$ e a $749 \mathrm{~m}$ de altitude. O clima na região é classificado como Aw (Koppen), que representa clima tropical com chuvas no verão. Os dados de temperatura e precipitação durante o período experimental encontram-se na Figura 1.
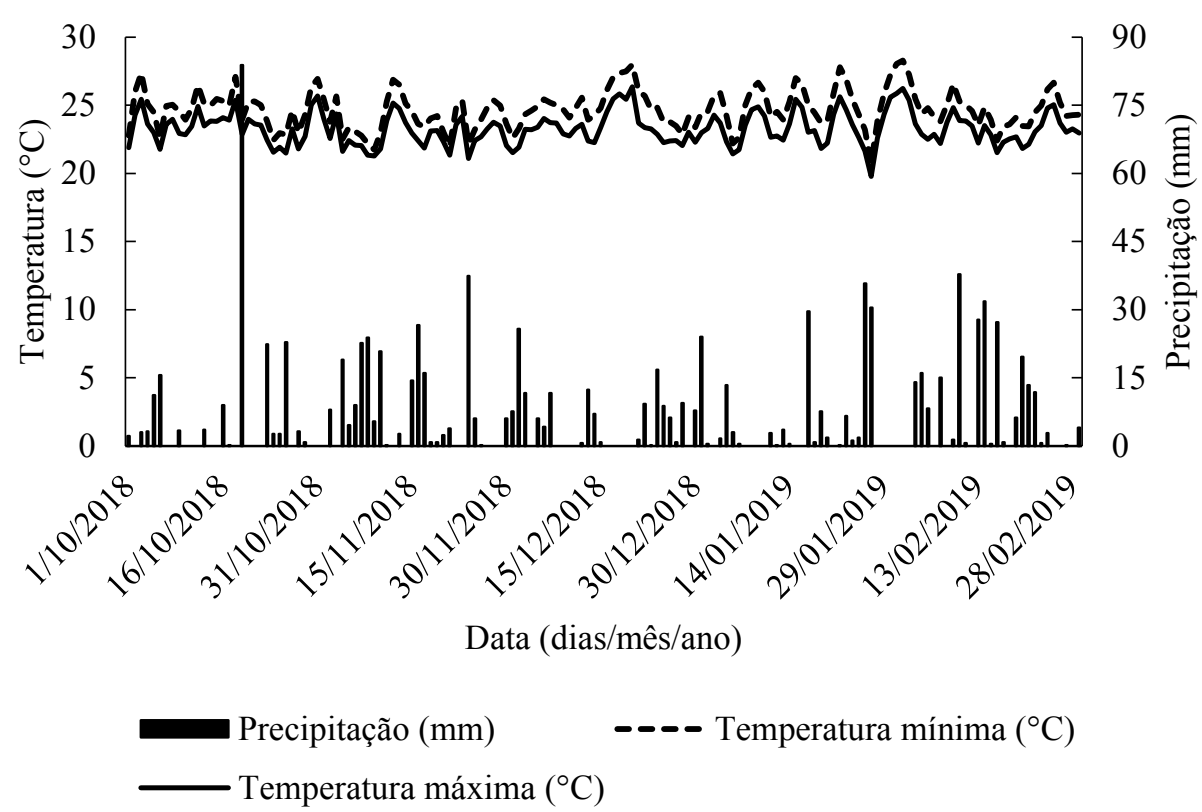

Fonte: INMET, Estação Metereológica de Rio Verde (GO).

Figura 1. Dados de precipitação e temperatura durante o período de condução do experimento. Rio Verde (GO), $2018 / 2019$.

Rev. Bras. Herb., v. 19, n. 1, e. 696, jan./mar., 2020 
I. M. PAULA et al.

O experimento foi instalado em esquema fatorial $(5 \mathrm{x}$ 2) em que o primeiro fator foi composto por níveis crescentes de infestação de capim-amargoso, 0, 2, 4, 6 e 8 plantas $\mathrm{m}^{-2}$. O segundo fator foi representado por duas cultivares de soja (Garra IPRO ${ }^{\circledR}$ com grupo de maturação 6,3 e ST797 IPRO $^{\circledR}$ com grupo de maturação 7,9). As unidades experimentais corresponderam a cinco linhas de soja (0,5 m entrelinhas) com cinco metros de comprimento. Bordaduras de $1 \mathrm{~m}$ em cada extremidade foram descontadas para o transplante de capim-amargoso e para as avaliações pertinentes. $\mathrm{O}$ experimento foi instalado em delineamento em blocos casualizados, com 4 repetições.

Sementes de capim-amargoso foram semeadas em bandejas contendo 200 células $(2 \times 2 \times 3 \mathrm{~cm})$ preenchidas com substrato MacPlant ${ }^{\circledR}$. Quando as plântulas apresentavam duas folhas, o transplantio na área experimental foi realizado manualmente, de modo que, em cada parcela, fossem transplantadas o número necessário para formar a infestação respectiva a cada tratamento. A soja foi semeada no mesmo dia, respeitando a densidade de semeadura recomendada pelo fabricante de cada cultivar $\left(\right.$ Garra IPRO ${ }^{\circledR}$ - 19 sementes $\mathrm{m}^{-1}$; ST797 IPRO $^{\circledR}-15$ sementes $\mathrm{m}^{-1}$ ). Para a semeadura da soja, foi utilizada semeadora mecanizada, realizando a adubação no sulco com $430 \mathrm{~kg} \mathrm{ha}^{-1}$ do fertilizante 4-20-18. Todos os tratos culturais foram realizados conforme as recomendações descritas por França-Neto et al. (2016). A área experimental foi mantida livre da presença de plantas daninhas com capinas semanais, de modo a evitar interferência de outras espécies além do capim-amargoso.

A colheita da soja foi realizada manualmente, coletando todas as plantas da área útil das unidades experimentais. Com a finalidade de padronizar o estádio de colheita de cada cultivar, estas foram colhidas separadamente (colheita da cultivar Garra IPRO ${ }^{\circledR}$ realizada em 06/02/2019 e ST797 IPRO ${ }^{\circledR}$ em 26/02/2019). As plantas de ambas as cultivares estavam em estádio R7-R8, ou seja, entre o início da maturação e maturação plena. As plantas foram trilhadas com uma trilhadora de grãos portátil e os grãos foram armazenados em sacos de $10 \mathrm{~kg}$. As sementes foram armazenadas em estufa de circulação forçada a $40{ }^{\circ} \mathrm{C}$. Para a padronização entre as duas cultivares, ambas foram retiradas da estufa quando atingiram umidade de $12 \%$. Depois do processo de secagem, duas amostras de cada unidade experimental contendo aproximadamente $0,5 \mathrm{~kg}$ de sementes foram retiradas, identificadas e armazenadas em sacos de papel a $4{ }^{\circ} \mathrm{C}$.

No Laboratório de Sementes da Universidade de Rio Verde, procedeu-se as seguintes avaliações em 50 sementes coletadas aleatoriamente de cada amostra (duas amostras por unidade experimental): porcentagem de germinação e vigor em papel germitest, contagem de sementes normais, anormais e mortas. Todas as metodologias foram seguidas conforme recomendações contidas no manual sobre Regras para Análise de Sementes (MAPA, 2009).

Os dados foram submetidos ao teste de Shapiro-Wilk $(p \leq 0,05)$ para verificação da normalidade dos resíduos. Os dados foram então submetidos ao teste $\mathrm{F}(p \leq 0,05)$ e quando verificada interação entre os fatores, procedeu-se o desdobramento do nível de densidade de capim-amargoso dentro de cada nível de cultivar, utilizando regressão linear $(p \leq 0,05)$. Os dados também foram analisados com base nos efeitos principais de cada cultivar. O programa estatístico utilizado foi o SISVAR (FERREIRA, 2011).

\section{Resultados e Discussão}

Para a variável sementes normais, houve interação significativa entre os fatores $(p=0,0028)$. Observou-se ajuste linear negativo do número de sementes normais em função da densidade de capim-amargoso apenas para a cultivar ST797 IPRO ${ }^{\circledR}$. Existem evidências de que se perde uma semente normal (perda de $2 \%$ ) a cada 1,3 plantas de capimamargoso $\mathrm{m}^{-1}$ em convivência com a cultivar ST797 IPRO ${ }^{\circledR}$ (Figura 2)

$\mathrm{O}$ número de sementes mortas também apresentou interação significativa entre os fatores $(p=0,0020)$. O ajuste da regressão permitiu verificar que para cada 1,8 plantas de capim-amargoso $\mathrm{m}^{-1}$, aumenta-se uma semente morta (2\%) para a cultivar ST797 IPRO ${ }^{\circledR}$. Assim como para a variável número de sementes normais, o número de sementes mortas não apresentou resposta em função da densidade de capimamargoso para a cultivar Garra IPRO ${ }^{\circledR}$ (Figura 2).

Para a variável germinação de sementes, não houve interação entre os fatores $(p>0,005)$, entretanto, optou-se por realizar o desdobramento em função da resposta encontrada para as variáveis discutidas anteriormente. Neste sentido, verificou-se ajuste da porcentagem de germinação em função da densidade de capim-amargoso para a cultivar ST797 IPRO $^{\circledR}$. É possível observar perdas de $1 \%$ na germinação a cada uma planta de capim-amargoso em convivência com esta cultivar (Figura 2).

Ao considerar a infestação máxima de capimamargoso ( 8 plantas $\mathrm{m}^{-1}$ ) observou-se perdas de $32 \%$ no número de sementes normais, $15 \%$ de sementes mortas e $16 \%$ na germinação para a cultivar ST797 IPRO ${ }^{\circledR}$. Com base na instrução normativa $\mathrm{n}^{\circ} 45$, de 17 de setembro de 2013, o padrão mínimo de germinação para a comercialização de sementes de soja C1 e C2 é de $80 \%$ (MAPA, 2013). Contudo, altas infestações de capimamargoso podem ocasionar perdas de até $16 \%$ de germinação, sem considerar outros fatores bióticos e abióticos que contribuem ainda mais para esta perda, tais como, colheita acima ou abaixo da umidade recomendada, equipamento de colheita desregulado e microclima favorável para a ocorrência de pragas e doenças, entre outros.

Ao comparar os sistemas de cultivo empregados no Estado de Goiás, Pereira e Velini (2003) observaram a ocorrência de 10 a até 50 plantas de capim-amargoso $\mathrm{m}^{-2}$ antes da semeadura da soja. Tal fato demonstra que as infestações podem alcançar níveis ainda maiores do que avaliados no presente trabalho, e consequentemente, ocasionar prejuízos mais expressivos em campos de produção de sementes que o controle da comunidade infestante não é realizado dentro dos padrões requeridos. 
I. M. PAULA et al.
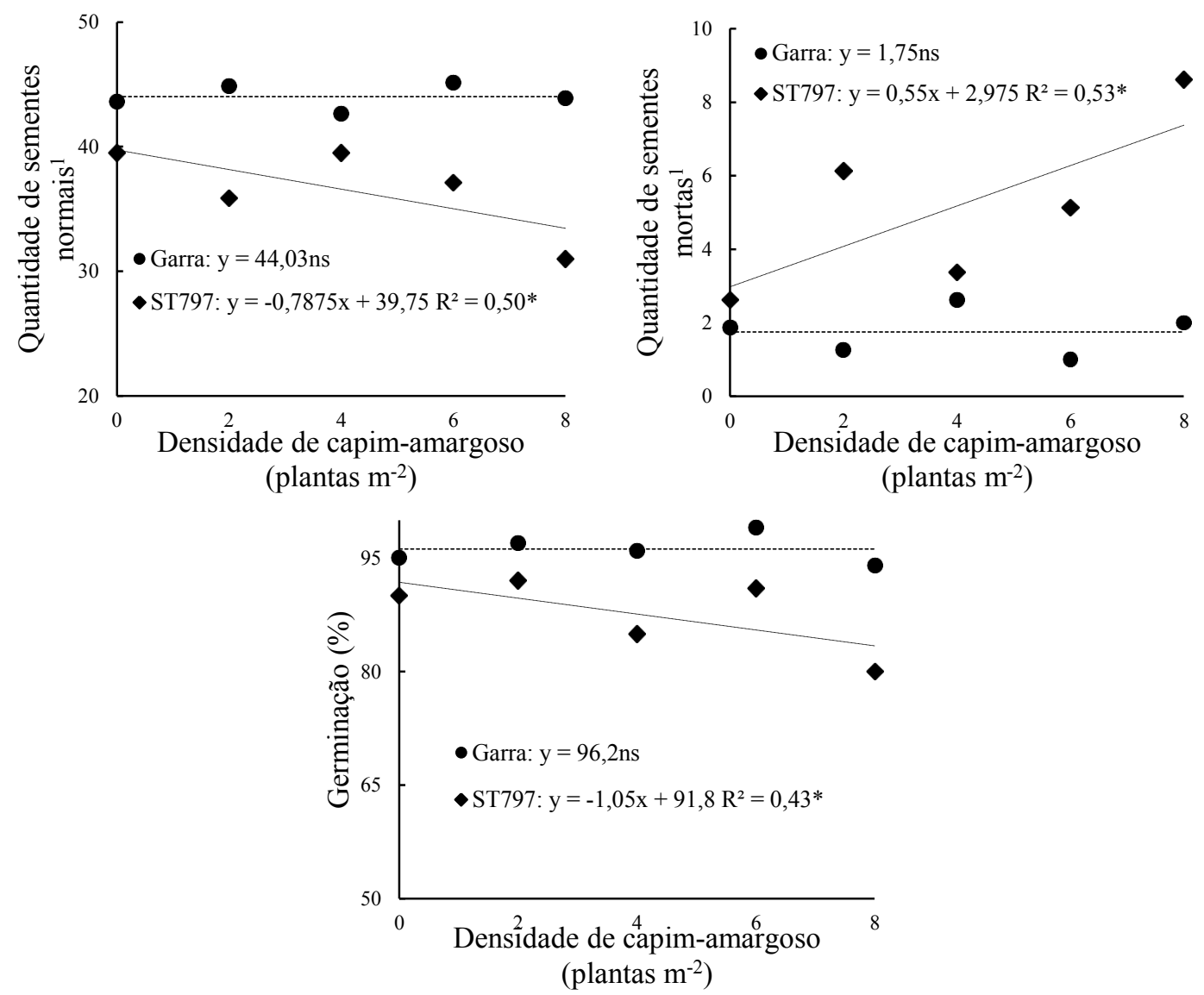

${ }^{1}$ Amostra de 50 sementes; * $\mathrm{e}^{\mathrm{ns}}$ : Significativo e não significativo a 5\% de probabilidade.

Figura 2. Resposta na qualidade de sementes produzidas de soja em função da densidade de infestação de capim-amargoso em duas cultivares de soja. Rio Verde (GO), 2018/2019. P-valor shapiro-wilk para sementes normais = 0,13; para sementes mortas =0,11; e para germinação $=0,8$.

A competição por recursos do meio como água, luz, nutrientes do solo e espaço físico entre duas espécies em convivência consiste em um dos processos que causa a interferência de uma planta daninha sobre a cultura (PITELLI, 2015). Obviamente, a redução no aproveitamento desses recursos pelas plantas de soja em função da infestação de capim-amargoso pode influenciar negativamente nos processos fisiológicos, e por fim afetar a qualidade das sementes produzidas. Se existe competição por água, por exemplo, o déficit hídrico causado pela interferência pode prejudicar a condutância estomática, a transpiração e a temperatura na câmara estomática durante o estádio R5-R6 (formação de grãos) (TAVARES et al., 2013).

O sombreamento proporcionado pelo capimamargoso a soja limita a taxa fotossintética, além de reduzir a relação vermelho/vermelho distante no ambiente. Isto faz com que as plantas inativem a ação do fitocromo B, o que desencadeia uma série de eventos para a produção de auxinas. O resultado é o alongamento dos entrenós, epinastia e senescência precoce (FIOREZE et al., 2013; BALLARÉ, 2017). O efeito na qualidade de sementes pode ser considerado indireto, pois a planta utiliza energia para competir nos estádios de desenvolvimento primordiais para a formação de sementes (estádio vegetativo).

Os percevejos são apontados como as principais pragas para produtores de sementes de soja (GOMES et al., 2012; RIBEIRO et al., 2016). Apesar de não mensurado neste trabalho, o capim-amargoso presente nas entrelinhas da soja pode ter servido de habitat para ninfas e adultos de percevejos se hospedarem, fazendo com que estes insetos proporcionassem danos às sementes de soja pela sucção destas estruturas reprodutivas.

Com base na comparação dos efeitos principais das cultivares, a média geral de germinação foi de $96,2 \%$ para a Garra IPRO $^{\circledR}$, independentemente da densidade de convívio com o capim-amargoso, enquanto que na ST797 IPRO ${ }^{\circledR}$, o valor médio foi de aproximadamente $87,6 \%$, considerando as densidades crescentes de infestação da planta daninha. A ST797 IPRO ${ }^{\circledR}$ apresentou elevada quantidade de sementes anormais em relação à Garra IPRO ${ }^{\circledR}$ (Tabela 1). Além disso, verificou-se que a Garra IPRO ${ }^{\circledR}$ apresentou maior vigor de sementes em detrimento à ST797 IPRO ${ }^{\circledR}$, fato que indicada maior potencial de estabelecimento da cultura após o início do processo germinativo e de emergência. 
I. M. PAULA et al.

Tabela 1. Comparação dos efeitos isolados das cultivares Garra IPRO $^{\circledR}$ e ST797 IPRO ${ }^{\circledR}$ com relação ao vigor e a quantidade de sementes anormais. Rio Verde (GO), 2018/2019.

\begin{tabular}{|c|c|c|}
\hline Cultivar & Vigor (\%) & Quantidade de sementes anormais 1 \\
\hline Garra IPRO $^{(R)}$ & $89,0 \quad \mathrm{a}$ & $4,2 \quad \mathrm{a}$ \\
\hline ST797 IPRO $^{\circledR}$ & $74,8 \quad \mathrm{~b}$ & $8,2 \quad b$ \\
\hline $\mathrm{CV}(\%)$ & 7,23 & 45,81 \\
\hline
\end{tabular}

${ }^{1}$ Amostra de 50 sementes; * Médias seguidas de letras iguais na coluna não diferem significativamente pelo teste $\mathrm{F}$ a $5 \%$ de probabilidade.

A cultivar $\mathrm{ST797}$ IPRO $^{\circledR}$ demonstrou maior sensibilidade à matocompetição, no que se refere a qualidade de sementes, quando comparada com a Garra IPRO $^{\circledR}$, visto que os valores apresentados na Tabela 1 consideram a média de todos os tratamentos contendo densidades crescentes de convivência das plantas de soja com o capim-amargoso. Souza et al. (2019) não constataram diferenças na produtividade entre duas cultivares de soja de ciclos distintos submetidas a competição com plantas daninhas. Apesar disto, no trabalho supracitado, não foi avaliada a influência do convívio com a comunidade infestante sobre a qualidade de sementes de soja, fato que impossibilita a inferência do fator ciclo da cultura sobre este parâmetro.

É possível que a cultivar Garra IPRO $^{\circledR}$ apresente maior habilidade competitiva entre as cultivares quanto a eficiência de uso da água e nutrientes, eficiência na assimilação de carbono e taxa de crescimento, estando assim, menos suscetível a competição com o capimamargoso. Além disso, por apresentar ciclo mais extenso, a cultivar ST797 IPRO $^{\circledR}$ foi exposta à um maior período de tempo as condições desfavoráveis geradas pela presença das plantas de capim-amargoso na entrelinha da cultura, fato que dificultou o processo de perda de umidade das sementes, bem como expôs estas a um intervalo maior em convivência com os ataques de percevejo.

$\mathrm{O}$ capim-amargoso adulto pode ser eficientemente controlado com herbicidas inibidores da Acetil-coAcarboxilase (ACCase) em pós-emergência (ZOBIOLE et al., 2016). Entretanto é fundamental também a aplicação de herbicidas em pré-emergência tais como inibidores da síntese de carotenoides, inibidores do crescimento inicial, inibidores da ALS, entre outros (GEMELLI et al., 2012). Alternativas não químicas, como o controle cultural, capinas, uso de cobertura morta e rotação de culturas são bem-vindas no manejo integrado desta planta daninha. Mais estudos são necessários para mensurar os danos causados por plantas daninhas na qualidade de sementes de soja, visto que avaliações em diferentes ambientes, cultivares e densidade de infestação podem fornecer informações fundamentais para alertar produtores de sementes sobre os danos causados pela convivência com a comunidade infestante.

\section{Conclusão}

A qualidade de sementes não foi prejudicada em função da infestação de capim-amargoso para a cultivar de soja Garra IPRO $^{\circledR}$. Para a cultivar ST797 IPRO $^{\circledR}$, quanto maior a infestação de capim-amargoso, maior a redução na germinação, o número de sementes mortas e menor o número de sementes normais.

\section{Agradecimentos}

Agradecimento ao Conselho Nacional de Desenvolvimento Científico e Tecnológico (CNPq) pelo suporte financeiro para execução de parte deste trabalho por meio de recurso disponibilizado na Chamada Universal $n^{\circ}$ $28 / 2018$

\section{Referências}

Adegas, F. S.; Gazziero, D. L. P.; Silva, A. F.; Concenço, G. Growth analysis of sourgrass: does herbicide resistance affect its development? Journal of Agricultural Science, v. 11, n. 11, p. 214-222, 2019.

Ballaré, C. L. Phytochrome responses: think globally, act locally. Trends in Plant Science, v. 22, n. 11, p. 909-911, 2017.

Barnes, E. R.; Jhala, A. J.; Knezevic, S. Z.; Sikkema, P. H.; Lindquist, J. L. Common ragweed (Ambrosia artemisiifolia L.) interference with soybean in Nebraska. Agronomy Journal, v. 110, n. 2, p. 646-653, 2018.

CONAB - Companhia Nacional de Abastecimento Boletim Grãos, Setembro 2019. Disponível em: <https:// www.conab.gov.br/info-agro/safras/graos/boletim-da-safrade-graos>. Acesso em: 03/10/2019.

Correia, N. B.; Danilussi, M. T. Y., Albrecht, A. J. P.; Albrecht, L. P.; Lorenzetti, J. B.; Barroso, A. A. M. Interferência de capim-amargoso e nível de dano econômico na soja. In: Anais do Congresso Brasileiro de Fitossanidade, 5, 2019, Curitiba. Anais... Curitiba: CONBRAF, 2019.

Ferreira, D. F. Sisvar: a computer statistical analysis system. Ciência e Agrotecnologia, v. 35, n. 6, p. 1039-1042, 2011.

Fioreze, S. L.; Rodrigues, J. D.; Carneiro, J. P. C.; Silva, A. A; Lima, M. B. Fisiologia e produção da soja tratada com cinetina e cálcio sob deficit hídrico e sombreamento. Pesquisa Agropecuária Brasileira, v. 48, n. 11, p. 14321439, 2013. 
França-Neto, J. B.; Krzyzanowski, F. C.; Henning, A. A.; Pádua, G. P.; Lorini, I.; Henning, F.A. Tecnologia da produção de semente de soja de alta qualidade. Londrina: Embrapa Soja, 2016. 82 p.

Gazziero, D. L. P.; Adegas, F. S.; Silva, A.; Concenço, G. Estimativas de perdas de rendimento na soja devido à interferência do capim-amargoso. Planta Daninha, v. 37, e019190835, 2019.

Gemelli, A.; Oliveira Jr., R. S.; Constantin, J.; Braz, G. B. P.; Jumes, T. M. C.; Oliveira Neto, A. M.; Dan, H. A.; Biffe, D. F. Aspectos da biologia de Digitaria insularis resistente ao glyphosate e implicações para o seu controle. Revista Brasileira de Herbicidas, v. 11, n. 2, p. 231-240, 2012.

Gomes, G. D. R.; Benin, G; Rosinha, R. C.; Galvan, D.; Pagliosa, E. S.; Pinnow, C.; Silva, C. L.; Beche, E. Produção e qualidade fisiológica de sementes de soja em diferentes ambientes de cultivo. Semina: Ciências Agrárias, v. 33, n. 1, p. 2593-2604, 2012.

Licorini, L. R.; Gandolfo, M. A.; Sorace, M. A.; Osipe, R.; Cossa, C. A.; Osipe, J. B. Identificação e controle de biótipos resistentes de Digitaria insularis (L.) Fedde ao glyphosate. Revista Brasileira de Herbicidas, v.14, n. 2, p. 148-154, 2015.

Martins, J. F.; Barroso, A. A. M.; Alves, P. L. C. A. Effects of environmental factors on seed germination and emergence of glyphosate resistant and susceptible sourgrass. Planta Daninha, v. 35, e017164499, 2017.

MAPA - Ministério de Agricultura Pecuária e Abastecimento. Instrução Normativa ${ }^{\circ} 43,17$ de Setembro de 2013. Diário Oficial da União, Poder Executivo, Seção 1, p. 10.

MAPA - Ministério de Agricultura Pecuária e Abastecimento. Regras para Análises de Sementes. Brasília: MAPA/ACS, 2009, 399 p.

Oliveira Neto, A. A produtividade da soja: análises e perspectivas. Brasília: CONAB, 2016, v. 1, 34 p.

Ovejero, R. F. L.; Takano, H. K.; Nicolai, M.; Ferreira, A.; Melo, M. S.; Cavenaghi, A. L.; Christoffoleti, P. J.; Oliveira Jr., R. S. Frequency and dispersal of glyphosate-resistant sourgrass (Digitaria insularis) populations across Brazilian agricultural production areas. Weed Science, v. 65, n.2, p. 285-294, 2017.

Pereira, F. A. R.; Velini, E. D. Sistemas de cultivo no cerrado e dinâmica de populações de plantas daninhas. Planta Daninha, v. 21, n.3, p. 355-363, 2003.

Pitelli, R. A. O termo planta-daninha. Planta Daninha, v. 33, n. 3, p. 622-623, 2015.
Ribeiro, F. C.; Rocha, F. S.; Erasmo, E. A. L.; Matos, E. P.; Costa, S. J. Manejo com inseticidas visando o controle de percevejo marrom na soja intacta. Journal of Neotropical Agriculture, v. 3, n. 2, p. 48-53, 2016.

Souza, R. G.; Cardoso, D. B. O.; Mamede, M. C.; Hamawaki, O. T.; Sousa, L. B. Desempenho agronômico de soja sob interferência de plantas infestantes. Cultura Agronômica, v. 28, n. 2, p. 194-203, 2019.

Tavares, L. C.; Araújo Rufino, C.; Brunes, A. P.; Tunes, L. M.; Barros, A. C. S. A.; Peske, S. T. Desempenho de sementes de soja sob deficiência hídrica: rendimento e qualidade fisiológica da geração F1. Ciência Rural, v. 43, n. 8 , p. $1357-1363,2013$.

Vitorino, H. S.; Silva Jr., A. C.; Gonçalves, C. G.; Margins, D. Interference of a weed community in the soybean crop in functions of sowing spacing. Revista Ciência Agronômica, v. 48, n. 4, p. 605-613, 2017.

Zobiole, L. H. S.; Krenchinski, F. H.; Albrecht, A. J. P.; Pereira, G.; Lucio, F. R.; Rossi, C.; Rubin, R. S. Controle de capim-amargoso perenizado em pleno florescimento. Revista Brasileira de Herbicidas, v. 15, n. 2, p. 157-164, 2016. 